\title{
Intralipid therapy and adverse reproductive outcome: is there any evidence?
}

\author{
Parijot Kumar1,2, Kevin Marron² and Conor Harrity1,2,3 \\ 'Beaumont Hospital, Dublin, Ireland \\ 2RCSI University of Medicine and Health Sciences, Dublin, Ireland \\ 3ReproMed, Dublin, Ireland
}

Correspondence should be addressed to C Harrity: conorharrity@rcsi.ie

\begin{abstract}
Controversy exists regarding the benefits of intravenous intralipid therapy in patients with a poor reproductive history. It is frequently reported that there is no evidence to support the effectiveness, utility or safety for this treatment. While individual studies may be perceived as weak, a systematic review and meta-analysis were performed to determine if there is any advantage to patients. PubMed, Embase and Scopus searches were performed with the target populations being either recurrent pregnancy loss (RPL), or recurrent implantation failure (RIF) undergoing assisted reproductive technology (ART) and receiving intralipid infusions. These cohorts were compared with either placebo, no intervention or alternative treatments. The most relevant outcome measures were considered to be clinical pregnancy rate (CPR), live birth rate (LBR), implantation rate (IR) and miscarriage rate (MR). Twelve studies encompassing 2676 participants met the criteria for selection and were included and reviewed. Treatment of the target population with intralipid led to an improvement in IR (Odds Ratio (OR): 2.97, 2.05-4.29), pregnancy rate (OR: 1.64, 1.31-2.04), and LBR (OR: 2.36, 1.75-3.17), with a reduction in MR (OR: 0.2, 0.14-0.30). Although intravenous intralipid is not recommended as a routine treatment for recurrent miscarriage or implantation failure, there is enough data to suggest consideration in selected patients where routine testing is unremarkable, standard treatments have failed and immunological risk factors are present. The presence of abnormal uterine natural killer (UNK) cells needs more study as a target marker to determine those who could benefit.
\end{abstract}

\section{Lay summary}

There is controversy regarding the benefits and efficacy of intravenous intralipid therapy in patients with a poor reproductive history. It is frequently reported that there is no credible evidence to support their use. A situation we frequently face as medical professionals is patients asking us to consider immune therapy (such as intralipid) for reproductive failure where good quality embryos have been used. Intralipid infusions have been reported to improve pregnancy rates with IVF, and reduce the miscarriage risk in selected patient groups, but study results are not universally accepted. We have performed a detailed review and analysis of the literature to determine if there is any benefit to this immune treatment in specific patient groups. Our paper identified and analyzed 12 studies, finding that treatment with intravenous intralipid leads to an improvement in implantation, pregnancy and live birth rates, with a decrease in miscarriage rate. This study shows that there is evidence to suggest consideration of intralipid in certain patients where standard treatments have failed.

Key Words: - intravenous intralipid $\quad$ meta-analysis $\quad$ assisted reproduction $\quad$ pregnancy loss $\quad$ reproductive immunology

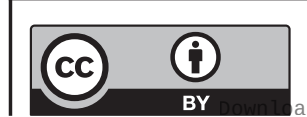




\section{Introduction}

Repeated Implantation failure (RIF) and recurrent pregnancy loss (RPL) are among the most challenging scenarios in reproductive medicine. The cause often remains unknown, leading to frustration and stress. As a result, some patients or physicians seek treatments without a strong supporting evidence base. It is important to fully evaluate these therapies, with a comprehensive discussion regarding potential risks and benefits. Assisted Reproduction has many of these 'Add-Ons', whose value has not been confirmed, often with additional cost implications (Macklon et al. 2019). One such intervention is intralipid (IL) to improve pregnancy outcomes. Causes of miscarriage can be difficult to elucidate and are often multifactorial. Chromosomal abnormalities are the main cause of early pregnancy failure, and the probability of a euploid embryo decreases with female age. Anatomical factors, infection, endocrine and thrombophilic abnormalities may also play a role (Ford \& Schust 2009, Pirtea et al. 2021, Rimmer et al. 2021). Implantation failure is a separate entity but with partially overlapping causes and treatments (Christiansen et al. 2006). The etiological factors of RIF are again primarily related to the embryo or endometrium, but may also include disorders of the implantation window and endometrial receptivity. Immunological factors remain a controversial cause for both failed implantation and pregnancy loss.

Early in the study of reproductive immunology, the role of peripheral blood natural killer (pNK) cells $(\mathrm{CD} 16+/ 56+$ dim $)$ in pregnancy failure was suggested (Wegmann et al. 1979). Peripheral and uterine natural killer cells (uNK, CD16-/56+bright) have very different phenotypes and functions (Koopman et al. 2003, Horowitz et al. 2013) leading to much confusion and misunderstanding. Over time a shift occurred, focusing on the endometrium and uNK cells. Multiple studies have shown that RIF/ RPL are associated with elevated NK cell numbers and activity, or higher concentrations of certain T-lymphocyte subpopulations (Sacks et al. 2012, Tang et al. 2013, Dakhly et al. 2016). Many leukocyte subsets possess the capacity to produce either pro-inflammatory (e.g. TNF- $\alpha$, IFN- $\gamma$ ) or anti-inflammatory (e.g. IL-10) monomeric cytokines (Jung et al. 1993). Stimulated cytokine expression in CD4+ $\mathrm{T}$ cells shows an association between increased expression of Th1 markers and the incidence of RPL/RIF (Kwak-Kim et al. 2003). Pro-inflammatory cytokines are thought to stimulate NK cell activatory KIR receptors, rendering them more cytotoxic (Szereday et al. 1997).

https://raf.bioscientifica.com

https://doi.org/10.1530/RAF-20-0052
Intralipid, developed in 1961, is a fat emulsion containing soybean oil, glycerin and egg phospholipids, used intravenously as part of parenteral nutrition in patients unable to tolerate an oral diet (Wretlind 1981, Driver et al. 1989, Granato et al. 2000, Meng et al. 2016). The main components are polyunsaturated fatty acids like linoleic, $\alpha$-linolenic, oleic, palmitic and stearic acid (Ota et al. 1985, Shreeve \& Sadek 2012, AbdolmohammadiVahid et al. 2016). A series of serendipitous observations suggested immunosuppressive properties. Increased bacteremia risk was seen in neonates using lipid-based parenteral nutrition (Jarvis et al. 1983, Freeman et al. 1990, Bansal et al. 2012). Intravenous lipid use also increased the risk of infective complications in surgical patients (Snydman et al. 1982). Lower rates of graft vs host disease after bone marrow transplantation were found in patients using soybean oil-based parenteral nutrition (Muscaritoli et al. 1998). Research in a reproductive setting inevitably followed. A study to assess trophoblast membrane vesicles for treating recurrent miscarriage found a greater success in the control group receiving IL (Johnson et al. 1991).

The unique hemochorial human placenta, and lack of a suitably similar animal model, means that RIF/RPL, have not significantly benefited from the insights that can be gained from studies of this nature. An early murine abortive model (CBAxDBA/2) identified a link between TNF- $\alpha$, IFN- $\gamma$, IL-2 and spontaneous miscarriage (Wegmann 1990). Mouse models show a key role for Tregs in the tolerance paradigm (Zenclussen et al. 2005), but this is not easily shown in humans. Mating studies also show that IL can be highly effective at preventing abortion in mice, and that this protection is prolonged (Chaouat et al. 1990, Clark 1994). Human research demonstrates that IL can modulate immune function by inhibiting NK cell cytotoxicity (Coulam \& Acacio 2012, Meng et al. 2016, Placais et al. 2020) by impairment of the macrophage antigen presentation function (Tezuka et al. 1988). A significant fall in NK activity and lymphokine-activated killer activity can be seen after IL administration (Sedman et al. 1991), and reduction in pro-inflammatory mediators produced by Th1 cells (Granato et al. 2000, Zenclussen et al. 2005, Abdolmohammadi-Vahid et al. 2016).

If classical causes for RIF/RPL are found, it is not unexpected that immunotherapy will not improve outcomes. It is established that only patients whose reproductive failure has an identifiable immunologic factor would be expected to respond to immunotherapy (Coulam 2020). Proper selection of appropriate patient subgroups within these diverse syndromes remains challenging. 
This systematic review and meta-analysis aims to report if there is any evidence of improving pregnancy outcomes with IL in women with RPL and/or RIF based on a compilation of existing knowledge. Additional aspects to determine where if immunological parameters exist which could be used as markers to indicate in which cases IL may have a beneficial role, and to assess if their efficacy has been compared with other immunotherapy agents.

\section{Methods}

\section{Literature search methodology}

PubMed, Embase and Scopus were the primary databases for literature search. Combinations of Medical Subject Headings (MeSH) and keywords were used to create subsets, including 'pregnancy' OR 'miscarriage' OR 'assisted reproduction' (ART) OR 'IVF' (in vitro fertilization) OR 'ICSI' (intra cytoplasmic sperm injections) OR 'implantation' OR 'Natural Killer' (NK). The subset was combined with 'Intralipid' using 'AND', to produce citations applicable to the research question. Searches included books, documents, clinical trials, meta-analysis, randomised controlled trials and reviews. No language restrictions were placed. Publications from 1949 to 2020 were included. To confirm all literature was reviewed the references and citations from primary papers and similar review articles were hand searched, along with a conference proceeding search to uncover any gray literature, which yielded a further 36 papers.

\section{Selection process}

Potential studies were selected in a two-step process. Citations identified by searches were scrutinized by title/ abstract, then full manuscripts were obtained for those meeting the inclusion criteria. Studies were selected if the target populations were women with RPL or RIF \pm IVF/ICSI treatment, using IL infusions. The cohorts were compared with placebo, no intervention or alternative treatment. Outcome measures were clinical pregnancy rate (CPR), live birth rate (LBR), implantation rate (IR) and/or miscarriage rate (MR). A total of 3032 studies were found on preliminary search. Once duplicates were removed 2369 remained for screening and eligibility assessment. The final decision for inclusion or exclusion of articles was done by a thorough manuscript evaluation, with 57 studies for eligibility assessment from which 45 were excluded. Twelve studies
( $n=2676,1592$ controls and 1084 treated with ILs) met the criteria for selection and were included for review.

\section{Data extraction}

Two authors ( $\mathrm{P} \mathrm{K}$ and $\mathrm{C} \mathrm{H}$ ) independently reviewed the manuscripts to determine if inclusion criteria were met. Data was extracted and compiled as per study parameters. Information collected included authors, publication year, study design, inclusion criteria, patient size, intervention used, controls, alloimmune assessment, and outcome measures. Predesigned forms were created to extract aggregate data. When missing data were encountered, attempts were to obtain individual data from the corresponding author.

\section{Statistical analysis}

Review Manager (RevMan v5.6) software (Cochrane Collaboration, Oxford, UK) was used for meta-analysis. A traditional weighted average meta-analysis was calculated, yielding a Mantel-Haenszel odds ratio with 95\% CIs, and heterogeneity investigated with $\mathrm{I}^{2}$ statistics. An odds ratio $(\mathrm{OR})>1.0$ indicates a positive benefit, with CIs, representing the degree of uncertainty, to assess if a difference is significant. Considerable heterogeneity was acknowledged as an $\mathrm{I}^{2}$ statistic of $75-100 \%$.

\section{Results}

\section{Study characteristics}

Twelve studies were included for analysis, with six RCTs (El-Khayat \& Sadek 2015, Check \& Check 2016, Dakhly et al. 2016, Meng et al. 2016, Singh et al. 2019, Al-Zebeidi et al. 2020). Remaining papers included five cohort studies (Coulam \& Acacio 2012, Harrity et al. 2018, Martini et al. 2018, Ehrlich et al. 2019, Placais et al. 2020) and one nonrandomized trial (Ndukwe 2011). The non-randomized study was deemed suitable due to well applied inclusion criteria ( $\geq 3$ failed transfers), a defined abnormality on immunological testing (elevated TH1:2 cytokine ratios), and relevant outcome measures. As with many other systematic reviews, high heterogeneity, and quality variations of the individual studies mean the overall results must be fully assessed and interpreted with care. There were a number of aspects to identify in these studies and their differences were to be noted. Study characteristics and outcome measures are described in Table 1. There were

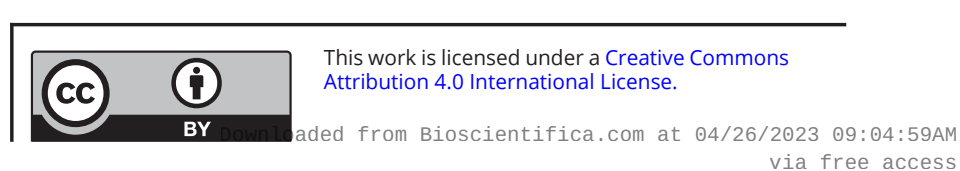




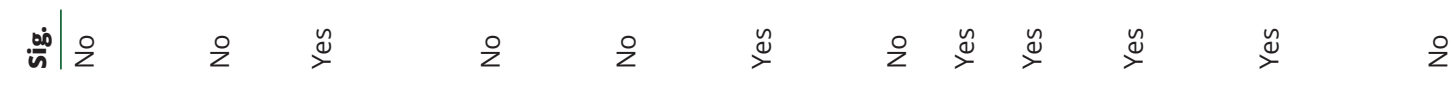

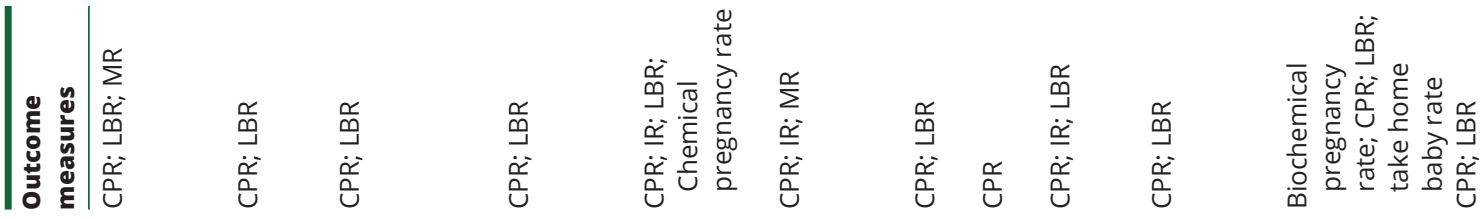

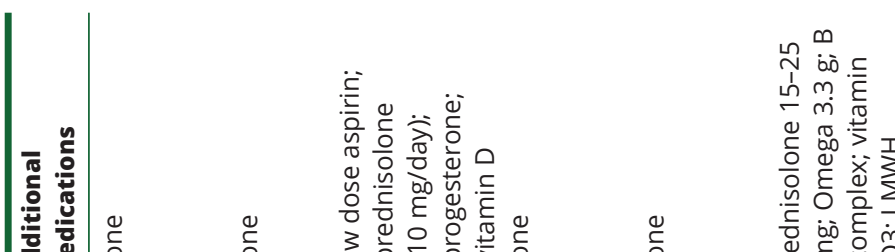

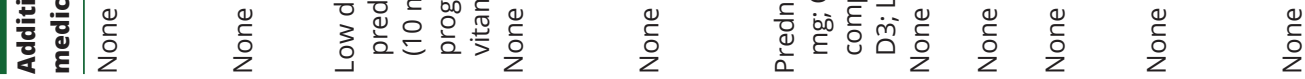
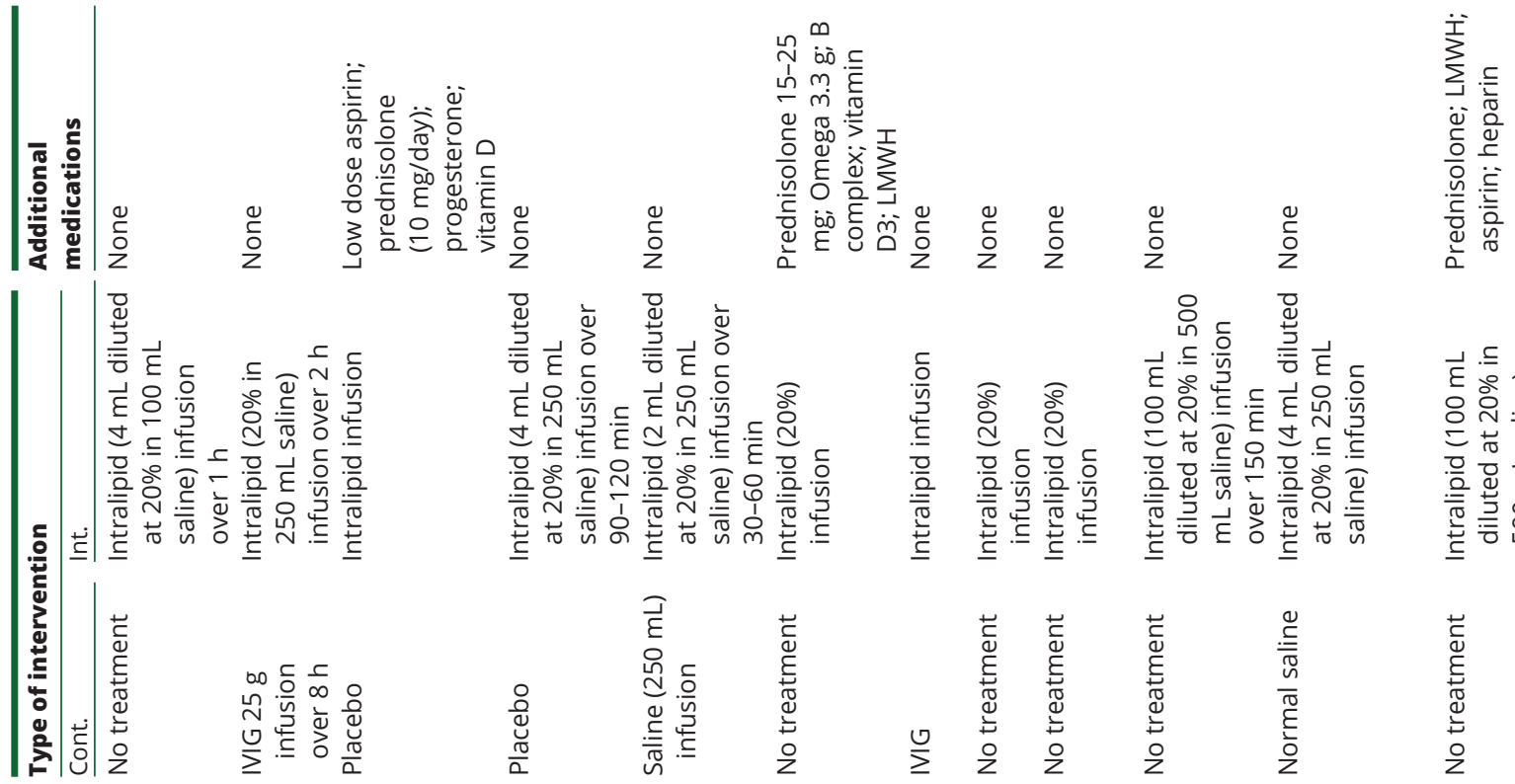

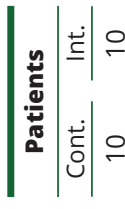
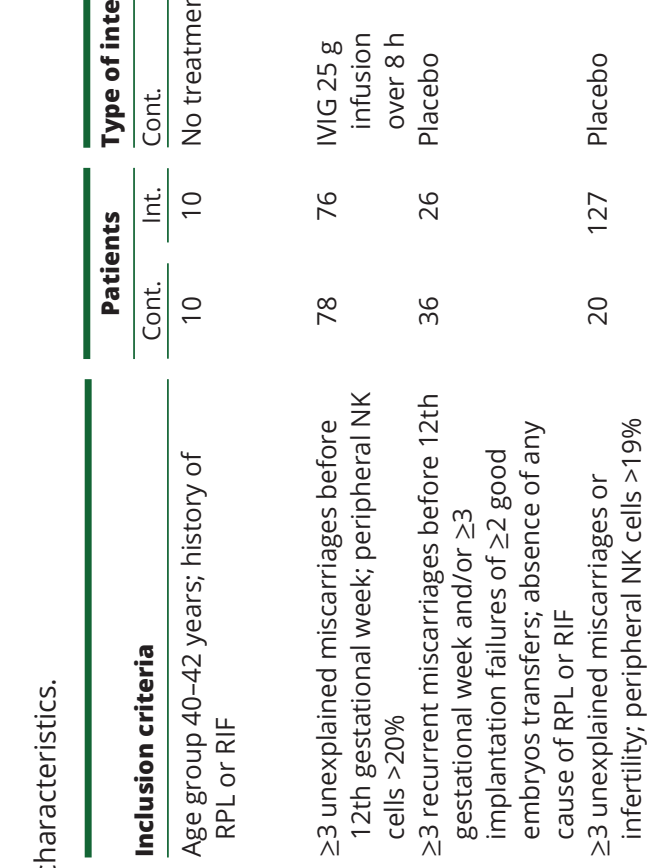

$\stackrel{2}{2}$

\&

$\stackrel{\infty}{\sim} \quad \dot{m}$



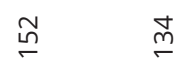

ㅇํ

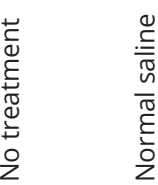

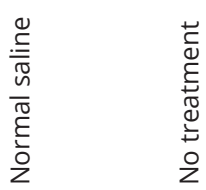

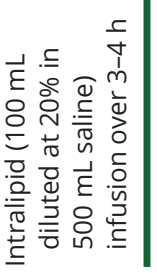

กิ

m

ปี ์ ธุ

ㅇํ

กู
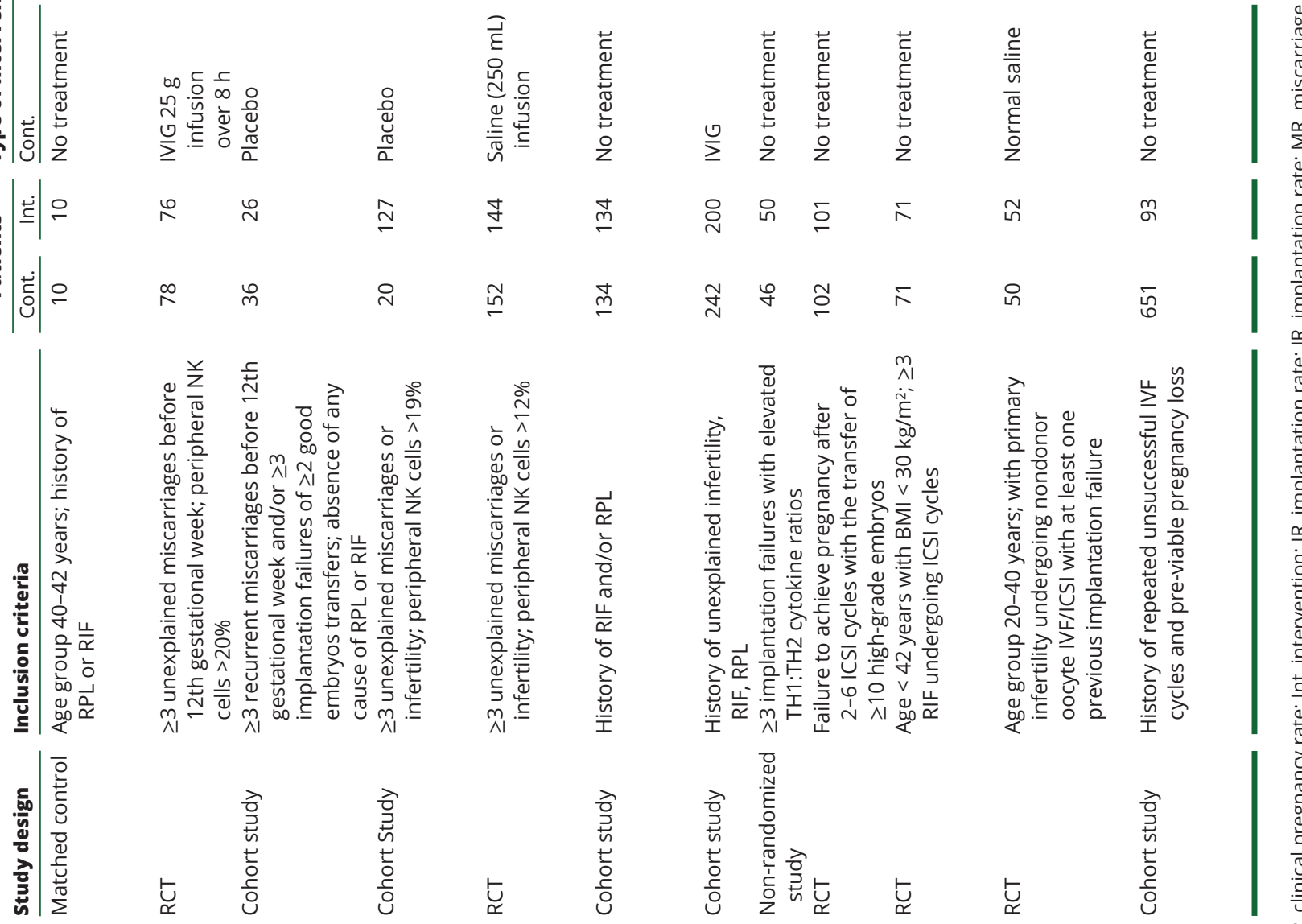

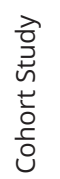

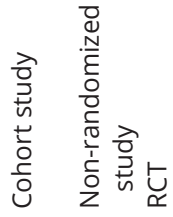

\section{旁

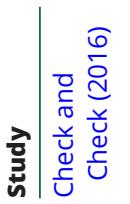

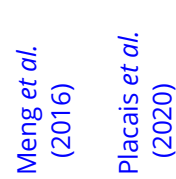

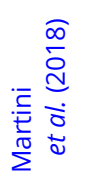

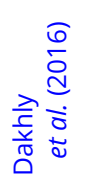
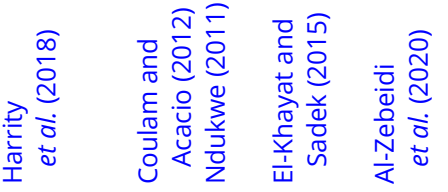

Ł

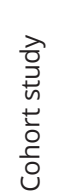


2676 participants evaluated, and subgroup analyses were performed to identify associations and trends.

\section{Intralipids vs no intervention (control/placebo)}

Analysing data from all studies and all patient subgroups (RPL and RIF) comparing IL vs placebo or no treatment identified ten trials, including five RCTs, with 2072 cases. Key outcome measures to compare were IR, CPR, MR and LBR. The beneficial, and statistically significant, effects of IL on these outcomes are demonstrated (Figs 1, 2, 3 and 4).

\section{Implantation rate}

IR, or the number of gestational sacs seen on ultrasound divided by the number of embryos transferred, is an important performance indicator for ART centers. A benefit is compensation for differences in practice between units using elective single embryo transfer strategies, and those using of multiple embryos. This measure is often not reported, and only two studies provided IR as an outcome following embryo transfer with a regime incorporating IL compared to placebo $(n=912)$. Study data reveal a strong and significant improvement in implantation following the addition of IL (OR: 2.97, 2.05-4.29, I² : 0\%) (Fig. 1 and Table 2).

\section{Pregnancy rate}

All studies Systematic review identified nine studies ( $n=1869$ ) reporting clinical pregnancy rate as an outcome measure. A significant improvement in CPR (OR: 1.64, $\left.1.31-2.04, \mathrm{I}^{2}: 67 \%\right)$ is found with IL use compared to no immunotherapy in the patient populations (Fig. 2A).

Randomized trials When cohort studies are excluded, four randomized trials remained $(n=402)$. Outcomes from RCTs alone remain similar, and support intervention, with a statistically significant improvement in CPR (OR: 1.51, 1.06-2.13, $\mathrm{I}^{2}: 52 \%$ ) following IL use, and less heterogeneity in the included studies (Fig. 2B).

\section{Miscarriage rate}

Asubgroupanalysisof patientswithonlyRPLwasperformed, by excluding those diagnosed with RIF or other etiologies, in order to assess if the attempted immunomodulatory regime had any effect on the miscarriage rate $(n=361)$. Interestingly, in this specific group of RPL cases, the published data clearly demonstrate that the addition of IL into the treatment has no impact on the ability to achieve a clinical pregnancy, with no difference in CPR between IL and control groups (OR: 1.17, 0.78-1.74, $\mathrm{I}^{2}$ : $82 \%$ ). This would not be unexpected, as these patients, by definition, do not have an issue with infertility/implantation at presentation. In this population, the primary concern is if IL therapy could reduce the risk of first-trimester loss, improving the probability of subsequent delivery. Metaanalysis of study data demonstrate a very significant reduction in MR (OR: 0.24, 0.15-0.39, $\mathrm{I}^{2}$ : 86\%) (Fig. 3A) and improvement in subsequent LBR (OR: 2.67, 1.79-3.98, I² : $53 \%$ ) with immunotherapy. The use of IL treatment does appear to be beneficial at reducing pregnancy loss in this high-risk population. The overall miscarriage rate for all patients, without selection by etiology, was also assessed ( $n=542)$. Again, study data demonstrates a significant reduction in MR with intralipid use (OR 0.20, 0.14-0.30, I2 75\%) (Fig. 3B).

\section{Live birth rate}

All studies Live birth rate (LBR) is the key measure by which many interventions in assisted reproduction are judged. Eight studies $(n=1068)$ reported this important outcome. Interestingly, there is a clinically relevant, and statistically significant, improvement in LBR (OR: 2.36, 1.75-3.17, $\mathrm{I}^{2}: 60 \%$ ) identified following IL therapy, compared to no intervention, in these high-risk patients (Fig. 4A).

Randomized trials An additional analysis was also performed using data from randomized controlled trials only. With the exclusion of the cohort studies, five RCTs

\begin{tabular}{|c|c|c|c|c|c|}
\hline \multirow[b]{2}{*}{ Study or Subgroup } & \multicolumn{2}{|c|}{ Intralipid } & \multicolumn{2}{|c|}{ Control } & \multirow[b]{2}{*}{ Weight } \\
\hline & Events & Total & Events & Total & \\
\hline Harrity 2018 & 106 & 347 & 38 & 295 & $80.0 \%$ \\
\hline Singh 2019 & 24 & 144 & 8 & 126 & $20.0 \%$ \\
\hline Total $(95 \% \mathrm{CI})$ & & 491 & & 421 & $100.0 \%$ \\
\hline $\begin{array}{l}\text { Total events } \\
\text { Heterogeneity: Chi } \\
\text { Test for overall effec }\end{array}$ & $\begin{array}{r}130 \\
00, \mathrm{df} \\
=5.79\end{array}$ & (P & $\begin{array}{r}46 \\
0.99) ; \\
00001)\end{array}$ & $I^{2}=0 \%$ & \\
\hline
\end{tabular}

Odds Ratio

M-H, Fixed, $95 \% \mathrm{CI}$

$2.97[1.97,4.48]$

$2.95[1.27,6.83]$

\section{$2.97[2.05,4.29]$}

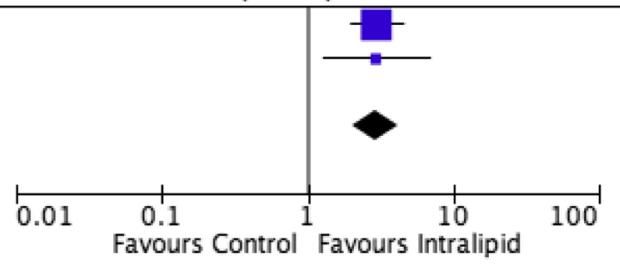

Odds Ratio $\mathrm{M}-\mathrm{H}$, Fixed, $95 \% \mathrm{Cl}$

Figure 1 Effect of Intralipid on IR vs control, all studies, all patients.

https://raf.bioscientifica.com

https://doi.org/10.1530/RAF-20-0052 (c) 2021 The authors Published by Bioscientifica Ltd

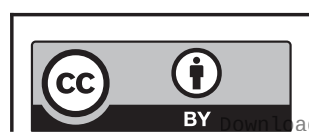

This work is licensed under a Creative Commons Attribution 4.0 International License. 


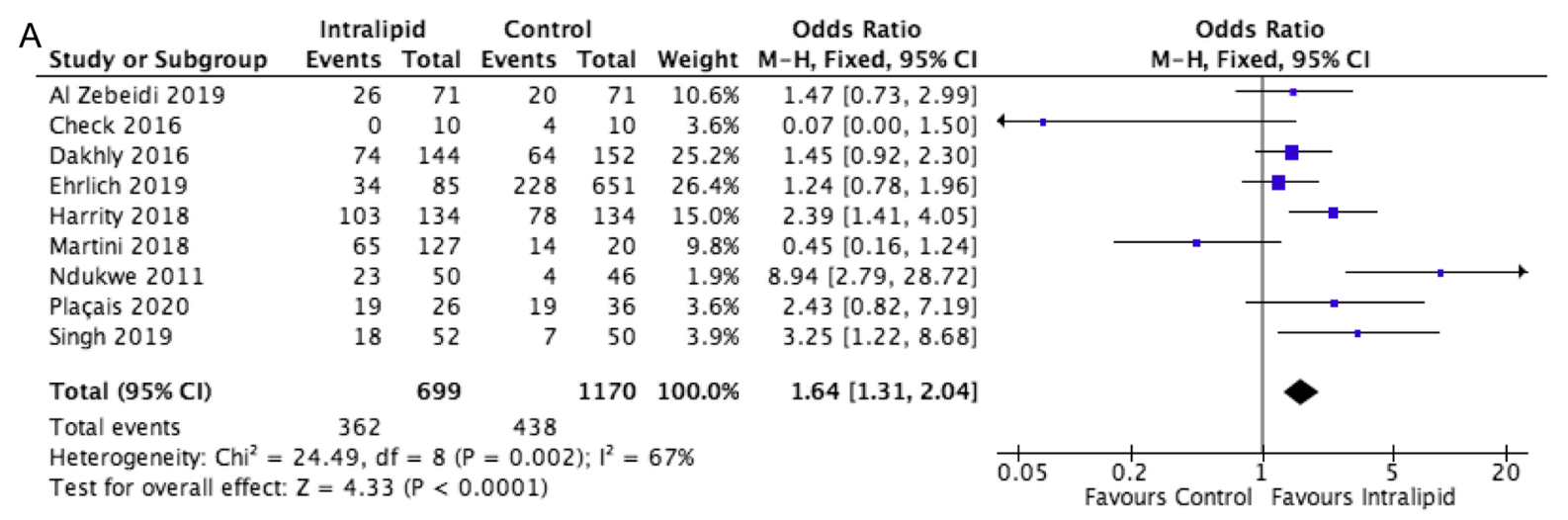

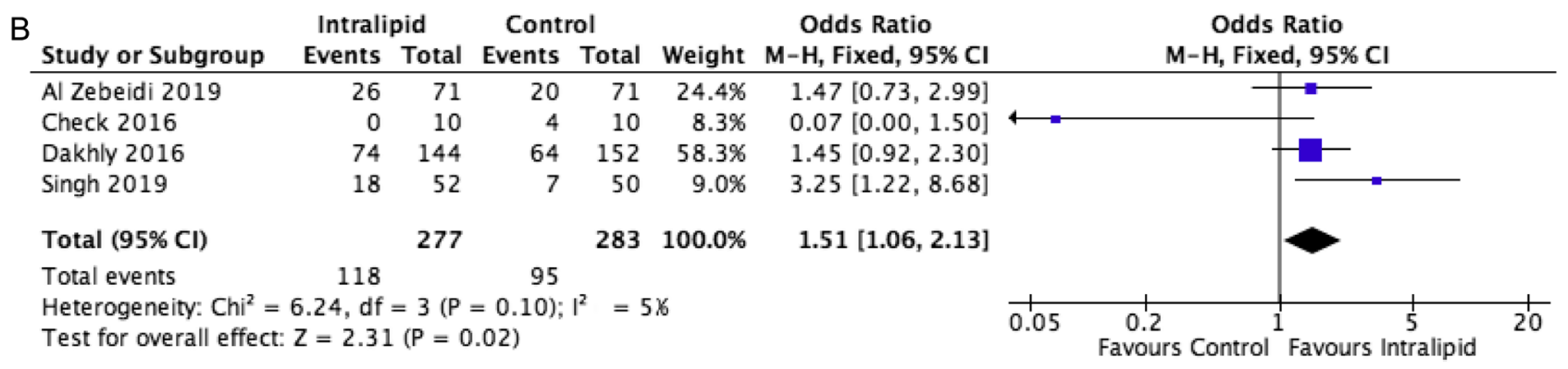

Figure 2 (A) Effect of intralipid on CPR vs control, all studies, all patients. (B) Effect of intralipid on CPR vs control, all studies, RCTs.

( $n=763)$ remain. Patient outcomes with randomized trials alone again demonstrate a statistically significant improvement in LBR (OR: 2.17, 1.54-3.05, I2 : 41\%) with IL use, and a reduction in study heterogeneity (Fig. 4B).

\section{Intralipid compared to alternative immunotherapy treatments}

Although the first study suggesting a role of IL therapy in the treatment of pregnancy loss was an interventional study, there is a paucity of research in this area since. Steroids and intravenous immunoglobulin (IVIG) comprised the early reproductive immunomodulatory regimes, but a transition from IVIG to IL for cost and safety reasons has been seen. A systematic review was performed for studies comparing IL with other immunotherapies.

\section{Intralipid vs IVIG}

Suppression of NK cell activity with IVIG has been reported in vitro (Ruiz et al. 1996, Roussev et al. 2007) and in vivo (Kwak et al. 1996), but whether this translates to improved outcomes is subject to debate. IVIG infusions may enhance LBR by decreased NK killing activity, increased suppressor T-cell activity, suppression of B cell autoantibody production, and actions on Fc receptors (Sewell \& Jolles 2002). Several meta-analyses indicate IVIG increases live birth in cases with RPL and positive immunological risk factors (Clark et al. 2006, Coulam \& Acacio 2012, Li et al. 2013, Meng et al. 2016). Subgroup analysis suggests improvement in LBR for secondary recurrent miscarriage, but not in primary RPL (Hutton et al. 2007). IVIG is not without risk, side effects range from headaches, nausea and vomiting, to more severe allergic reactions (Raziel et al. 1996, Meng et al. 2016). Immunoglobulins are produced from multiple blood donors, which is a rare risk of infection such as Hepatitis B, C, or HIV (Raziel et al. 1996). Due to high costs, the debate over efficacy, and potential adverse effects, IVIG has never been a recommended treatment. IL has gained interest as a safer, more acceptable choice and is shown to directly suppress NK cytotoxicity with equal efficacy as IVIG by in vitro (Ruiz et al. 1996) and in vivo (Roussev et al. 2008) assays. Literature review identified two studies ( $n=634$ ) comparing IVIG against IL, with LBR as the primary outcome. No difference in LBR was identified (OR: 1.02, 0.74-1.40, $\mathrm{I}^{2}$ : 63\%), suggesting equal efficacy (Fig. 5 and Table 2), suggesting IL to be at least as successful as IVIG in treating immune-mediated pregnancy loss in screened patients. 


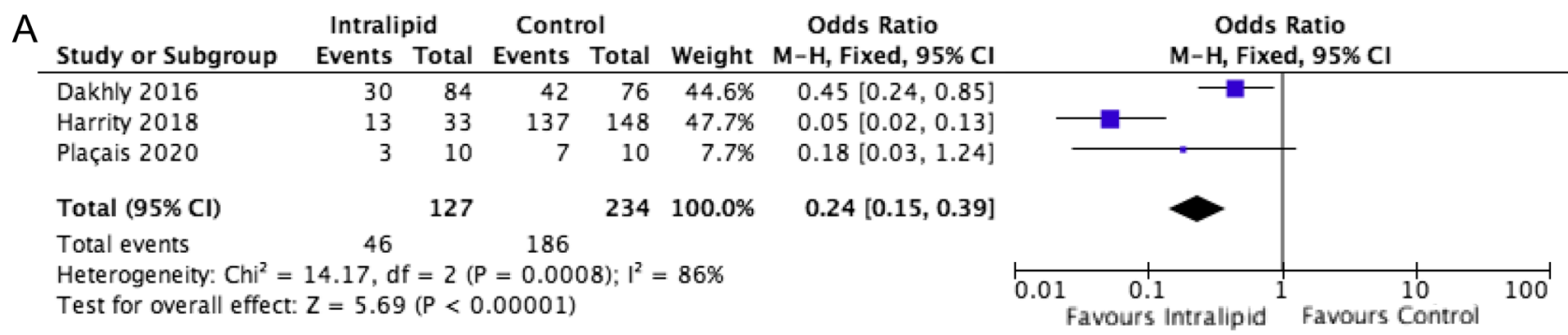

\begin{tabular}{|c|c|c|c|c|c|c|c|c|}
\hline Study or Subgroup & \multicolumn{2}{|c|}{ Intralipid } & \multicolumn{2}{|c|}{ Control } & Weight & $\begin{array}{c}\text { Odds Ratio } \\
\mathrm{M}-\mathrm{H}, \text { Fixed, } 95 \% \mathrm{Cl}\end{array}$ & \multicolumn{2}{|c|}{$\begin{array}{c}\text { Odds Ratio } \\
\mathrm{M}-\mathrm{H} \text {, Fixed, } 95 \% \mathrm{Cl}\end{array}$} \\
\hline Dakhly 2016 & 30 & 84 & 42 & 76 & $25.1 \%$ & $0.45[0.24,0.85]$ & $\rightarrow-$ & \\
\hline Harrity 2018 & 44 & 103 & 160 & 180 & $59.1 \%$ & $0.09[0.05,0.17]$ & & \\
\hline Ndukwe 2011 & 2 & 25 & 7 & 11 & $7.9 \%$ & $0.05[0.01,0.33]$ & $\longleftarrow$ & \\
\hline Plaçais 2020 & 7 & 19 & 11 & 16 & $6.7 \%$ & $0.27[0.06,1.09]$ & & \\
\hline Singh 2019 & 3 & 21 & 1 & 7 & $1.1 \%$ & $1.00[0.09,11.52]$ & & \\
\hline Total $(95 \% \mathrm{Cl})$ & & 252 & & 290 & $100.0 \%$ & $0.20[0.14,0.30]$ & & \\
\hline Total events & 86 & & 221 & & & & & \\
\hline $\begin{array}{l}\text { Heterogeneity: } \mathrm{Chi}^{2}= \\
\text { Test for overall effect }\end{array}$ & $\begin{array}{l}16.22, d f \\
Z=8.09\end{array}$ & $\begin{array}{l}f=4(P \\
(P<0\end{array}$ & $\begin{array}{l}P=0.003 \\
.00001)\end{array}$ & 3); $1^{2}=$ & & & $\begin{array}{|cc|}0.01 & 0.1 \\
\text { Favours Intralipid }\end{array}$ & $\begin{array}{c}10 \\
\text { Favours Control }\end{array}$ \\
\hline
\end{tabular}

Figure 3 (A) Effect of intralipid on MR vs control, RPL only. (B) Effect of intralipid on MR vs control, all studies.

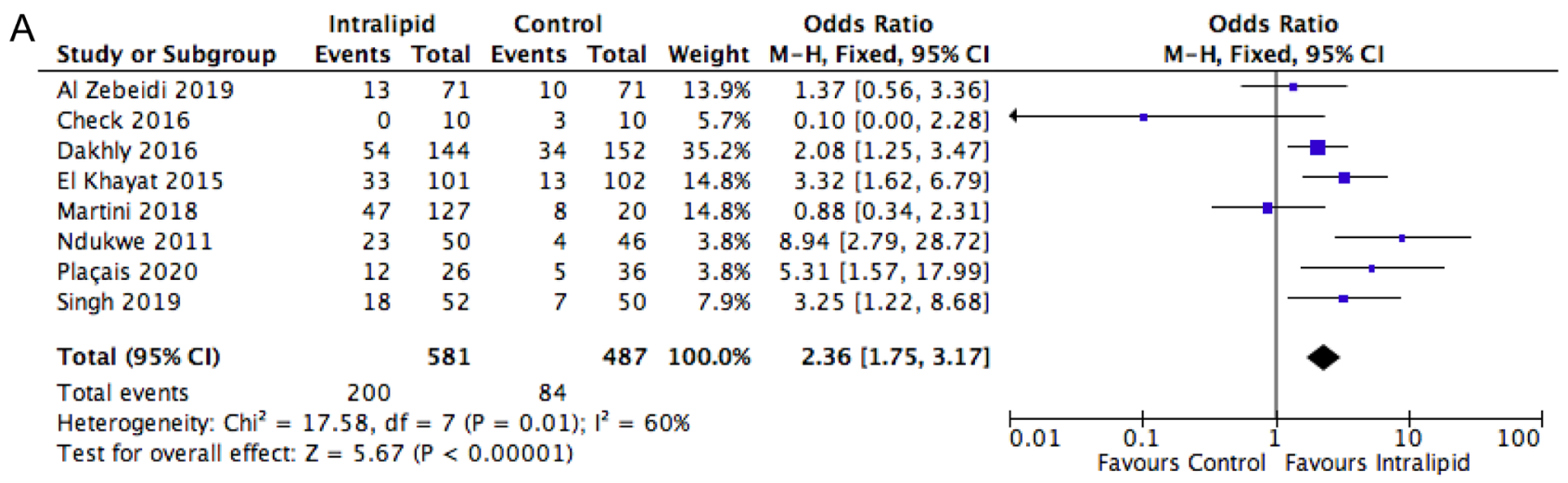

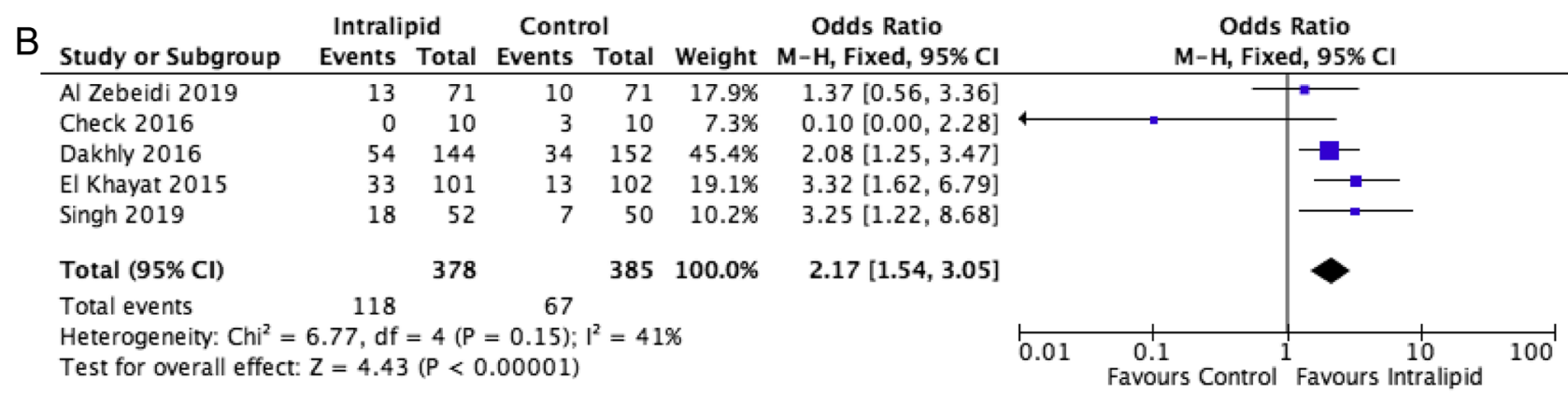

Figure 4 (A) Effect of intralipid on LBR vs control, all studies, all patients. (B) Effect of intralipid on LBR vs control, all studies, RCTs.

https://raf.bioscientifica.com

https://doi.org/10.1530/RAF-20-0052 (c) 2021 The authors Published by Bioscientifica Ltd

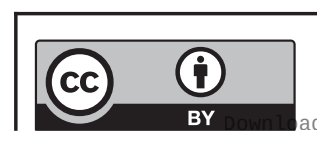

This work is licensed under a Creative Commons Attribution 4.0 International License. 
Table 2 Summary table showing intralipid outcomes across all the included studies, stratified by total trials, randomized control trials only, vs reproductive pregnancy loss only and vs IVIG, the odds ratio (OR) generated in each meta-analysis and the $95 \% \mathrm{CI}$ generated.

\begin{tabular}{l}
\hline Outcome \\
\hline Vs control (all studies included) \\
Clinical pregnancy \\
Live birth \\
Miscarriage \\
Implantation rate \\
Vs control (all patients, RCTs only) \\
Clinical pregnancy \\
Live birth \\
Vs control (RPL cases only, all studies included) \\
Clinical pregnancy \\
Live birth \\
Miscarriage \\
Vs IVIG (all studies included) \\
Live birth
\end{tabular}

\section{Intralipid vs corticosteroids}

Clinical benefits of oral corticosteroids in patients with adverse reproductive outcomes have been reported, but despite this, there is no consensus of therapeutic benefit. Steroid use is not recommended by most professional societies. Unfortunately, no trials were identified to compare prednisolone or other glucocorticoids with IL. A retrospective study using prednisolone to treat overactive endometrial immune profiles was identified but reported a beneficial effect on parameters in only $54.5 \%$ of cases, with a paradoxical deleterious effect in $29 \%$ where the immune profile actually worsened (Ledee et al. 2018a). Comparative interventional studies are needed to contrast the impact of steroids and IL.

\section{Intralipid use and abnormal immunological assessment}

A major criticism with reproductive immunotherapy has been patient selection criteria, or lack of. Ideally there should be a combination of treatment failure with a euploid embryo and proven abnormal markers on auto/alloimmune assessment before considering

\begin{tabular}{c}
\hline Studies \\
\hline 9 \\
8 \\
5 \\
2 \\
4 \\
5 \\
3 \\
3 \\
3 \\
2
\end{tabular}

\begin{tabular}{c}
\hline Participants \\
\hline 1869 \\
1068 \\
542 \\
912 \\
402 \\
763 \\
428 \\
529 \\
361 \\
634
\end{tabular}

\begin{tabular}{c}
\hline $\mathbf{O R}(95 \% \mathrm{Cl})$ \\
\hline $1.64(1.31,2.04)$ \\
$2.36(1.75,3.17)$ \\
$0.20(0.14,0.30)$ \\
$2.97(2.05,4.29)$ \\
$1.83(1.19,2.80)$ \\
$2.17(1.54,3.05)$ \\
$1.17(0.78,1.74)$ \\
$2.67(1.79,3.98)$ \\
$0.24(0.14,0.30)$ \\
$1.02(0.74,1.40)$
\end{tabular}

immunomodulation. A review to determine if any specific immunological abnormalities could predict a better response to IL treatment (Table 3 ) and analyze the effect of IL on individual immunological parameters (Table 4) is described.

\section{Uterine natural killer cells}

Although uNK play an important role in the maternal immune response to pathogens, they are primarily involved in trophoblastic invasion and angiogenesis (Khan et al. 2019). There is conflicting data on the impact of uNK cell concentrations and fertility, suggesting function, not just numbers, may be associated with pregnancy loss (Coulam 2020). Endometrial biopsy for uNK assessment is proposed as a marker for reproductive failure, but the literature review did not identify any studies testing this hypothesis in terms of patient selection for IL in combination with controls. An observational study was identified assessing uNK numbers (CD56 cells) by biopsy, uNK maturation and activity (IL14/FN-14 ratio) and the local Th1:2 Balance (Il-18:TWEAK) (Ledee et al. 2018a). In this trial a high LBR of 54\% (51/94) was achieved in poorer prognosis RIF patients with overactive endometrial profiles following IL treatment. There was also

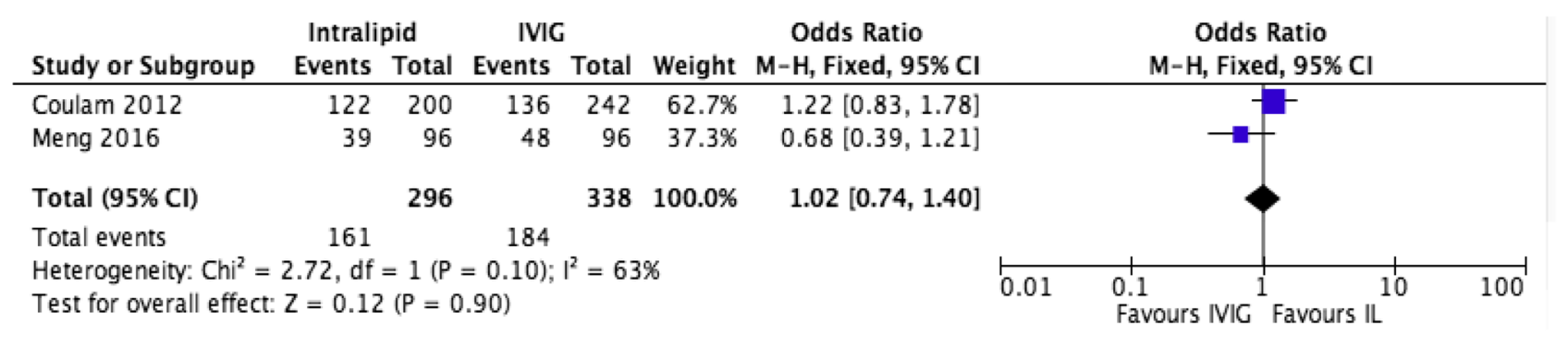

Figure 5 Effect of intralipid on CPR vs IVIG, all studies, all patients.

https://raf.bioscientifica.com

https://doi.org/10.1530/RAF-20-0052 (c) 2021 The authors Published by Bioscientifica Ltd

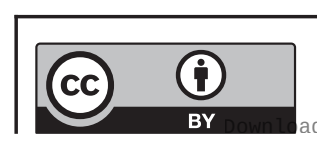

This work is licensed under a Creative Commons Attribution 4.0 International License. 
Table 3 Summary table showing intralipid outcomes vs no intervention across all the included studies, stratified by the use of immunological testing as an inclusion criteria.

\begin{tabular}{l}
\hline Diagnostic test \\
\hline uNK (endometrium) \\
No comparative studies \\
pNK (blood): two studies \\
$1>12 \%$ \\
$1>19 \%$ \\
Th1:2 cytokine ratio (blood): two studies \\
2 CPR and 1 LBR \\
\hline
\end{tabular}

Threshold level
NA
$>19 \%$
$>12 \%$

$\frac{\text { CPR }}{\text { NA }}$

P

0.51 vs 0.70

0.58 vs 0.50

Elevated 1

0.66 vs 0.46

\section{$-$}

0.12

0.15

$<0.001$

LBR

$P$

NA

0.37 vs 0.40

0.38 vs 0.22

0.80

0.005

${ }^{1}$ Elevated TH1:2 cytokine ratio defined as TNFa:IL-10 > 30.6 and/or IFNg:IL-10 > 20.5.NA, not assessed.

a significant decrease in each of the three biomarkers used to diagnose over-immune endometrial activation after IL use (Ledee et al. 2018a). The lack of a control/placebo group limits the interpretation of the results.

\section{Peripheral blood natural killer cells}

An association between pNK concentration/activity and the adverse reproductive outcome is proposed but a shortage of data using these markers as inclusion criteria for interventional trials is seen. Meta-analysis demonstrates higher pNK numbers in RPL cases compared to controls, but no difference in IVF LBR with elevated pNK numbers/activity (Seshadri \& Sunkara 2014). CD56+ve pNK cells typically comprise around $10 \%$ of peripheral blood lymphocytes (Robertson \& Ritz 1990), but reliable reproductive reference ranges have not been established, and no agreement on an upper threshold; $\mathrm{pNK} \geq 12 \%$ has been associated with poor reproductive outcome (Michou et al. 2003, Thum et al. 2004), but alternatively pNK $>18 \%$ are reported as specific for RPL/RIF (King et al. 2010). Two studies used elevated pNK levels as inclusion criteria. Using a cut-off of 19\%, no benefit was seen in CPR or LBR with IL treatment. Strangely, when a lower threshold of $12 \%$ was used, there was a significant improvement in LBR, although CPRs were no different. There is insufficient evidence to establish any conclusion regarding the use of pNK levels as a selection tool for IL use.

Table 4 Summary table showing a change in immunological testing parameters before and after intralipid treatment using data from Meng $2016(n=79)$ and Ledee 2018 (patients achieving pregnancy, $n=27)$.

\begin{tabular}{|c|c|c|c|}
\hline Diagnostic test & Pre-IL & Post-IL & $\boldsymbol{P}$ \\
\hline pNK conc ( $\%$ CD56+CD16+) & 26.1 & 24.4 & $<0.001$ \\
\hline pNK cytotoxicity (K562 assay) & 37.8 & 26.6 & $<0.001$ \\
\hline uNK count (CD56 cells/field) & 62.8 & 45.5 & 0.04 \\
\hline uNK activity (IL-15:Fn-14) & 3.6 & 0.79 & $<0.001$ \\
\hline Uterine TH1:2 (IL-18:TWEAK) & 0.18 & 0.08 & $<0.001$ \\
\hline $\begin{array}{l}\text { https://raf.bioscientifica.com } \\
\text { https://doi.org/10.1530/RAF-20-0052 }\end{array}$ & & Published by & $\begin{array}{l}\text { The authors } \\
\text { :ientifica Ltd }\end{array}$ \\
\hline
\end{tabular}

\section{Th1:Th2 cytokine ratios}

Th1:Th2 ratios have been associated with reproductive failure; Th1 cytokine excess may be detrimental for implantation and placental development, with similar issues suspected in the absence of Th2 cytokines (Chaouat 2007). Measurement of stimulated intracellular cytokine expression in $\mathrm{CD} 4+\mathrm{T}$ cells has been suggested to assess this. Systematic review identified two studies using elevated Th1:Th2 cytokine ratios for patient selection. A non-randomized trial reported a significant improvement in CPR and LBR with IL treatment in cases with elevated cytokines (Ndukwe 2011), and a cohort study reported improvement in IR, CPR and reduction in MR. No studies were identified that reported changes in pre- and postinfusion Th1:Th2 cytokine ratios to measure the in vivo effect of IL treatment.

\section{Discussion}

Although it is frequently reported that there is no evidence to support IL use for the adverse reproductive outcome, literature review demonstrates a growing body of published data, with 12 studies (including six RCTs) designed to answer important and relevant questions. Meta-analysis reveals higher IR, CPR and LBR with IL, and a reduction in MR, with all differences statistically significant. For certain obstetric complications, such as pregnancyinduced hypertension, pre-eclampsia, or intrauterine growth restriction, immunological maladaptation plays a significant role (Savasi et al. 2016). Although there is a clear understanding that normal endometrial immunological function, in particular uNK cells, is needed to allow implantation and early pregnancy development (van Mourik et al. 2009), there is much to learn about the consequences of changes in leukocyte numbers or activity. As a result, there remains great debate as to which tests or treatments, if any, should be recommended. 
Attempts to study peripheral blood lymphocytes as a marker of uterine immune dysfunction are controversial. Although pNK cells are reported to be elevated in women with RPL (Yamada et al. 2003), not all studies agree (Emmer et al. 1999, Souza et al. 2002, Wang et al. 2008). A criticism of hematological testing is that no physiological reason for a relationship between blood and endometrial NK levels should exist (Moffett-King 2002), and analysis shows no correlation between pNK and uNK concentrations (Clark 2010). Blood values are influenced by external dynamics and prone to fluctuations, so they tend to lack scientific credibility (Maecker et al. 2012, Moffett \& Shreeve 2016). Moves to focus on the uterine environment are increasing. Early endometrial analysis identified RPL cases have different patterns of CD4 and CD8 cells, an increase in percentage CD56 dim NK cells, and more B Lymphocytes (Lachapelle et al. 1996). RPL patients have more uNKs than controls, and prednisolone can significantly reduce the number of endometrial CD56 cells (Quenby et al. 2005). Differential gene expression patterns show that endometrial immune profiles are dysregulated in RIF/ RPL (Ledee et al. 2016). Changes in mRNA cytokine ratios, specifically IL-15/Fn-14 as a biomarker of uNK cell activation and ILI8/TWEAK to assess Th1:Th2 balance, can identify immune over/under activation, with an imbalance in these ratios in over $80 \%$ of RIF cases (Ledee et al. 2016). Endometrial flow cytometry demonstrates higher uNK levels in RIF, while B, pNK, and NK-T cells are higher in RPL (Harrity et al. 2019, Marron et al. 2019). An endometrial decidualization profile has been proposed, incorporating molecular analysis of decidualization/ implantation factors (FOXO1, GZMB, IL15, SCNN1A, SGK1, SLC2A1) to calculate a score identifying patients that may benefit from intervention (Wolff et al. 2003, Salker et al. 2011, Ruan et al. 2012, Vasquez et al. 2018, Coulam et al. 2020). NK activity can be significantly decreased by IL (Roussev et al. 2007). The effects can be lasting, with a duration of 4-9 weeks (Roussev et al. 2008). Other studies demonstrated decreased in vitro activation of T cells, and a reduction in cytokine secretion, with decreased TNF- $\alpha$, IL-2 and IL-1 $\beta$ (Granato et al. 2000, Ledee et al. 2018b). IL shows promise as treatment for overactive endometrial immune profiles (Ledee et al. 2016, Ledee et al. 2018b). Conversely, stimulatory measures should be employed and immunosuppression avoided in underactive profiles.

Reproductive immunotherapy should only be utilized if there is an identifiable alloimmune cause. If aneuploidy, systemic disease, endometrial receptivity or anatomical factors are the primary issue, then it is not surprising that immunomodulation is of no benefit. Inappropriate use, often at significant additional cost to patients, has done much reputational damage to this field. Older studies that attracted criticism often did not employ screening tests to identify patients with relevant immunological factors. Increasing the use of preimplantation genetic screening (PGT-A) can improve the LBR per transfer by excluding aneuploid embryos. Interestingly, PGT-A has shown that transfer of chromosomally normal blastocysts is not always successful, with at least $30 \%$ of euploid embryos failing to implant or ending with miscarriage (Franasiak \& Scott 2017). This may identify candidates for personalized screening and consideration of immunomodulation.

Although there is skepticism, only a single study demonstrates a disadvantageous effect of IL on outcome. Inclusion criteria was female age 40-42 years, and HFEA data reports a LBR of only $11.3 \%$ in these patients (Human Fertilization and Embryology Authority 2020). A higher LBR of $30 \%$ was seen in the controls, compared to $0 \%$ receiving IL. Aneuploidy is the most likely cause for implantation failure, and PGT-A was not incorporated into the cycles, with around $58-75 \%$ of embryos aneuploid at this age (Franasiak et al. 2014). Screening for alloimmune risk factors was also not used in the selection process. The authors hypothesized that IL may indeed be detrimental in older age groups, and this question would warrant more investigation.

Cost is a major benefit of IL compared to other immunomodulation agents. The product cost for Intralipid $20 \%$ is around $€ 7.45$ per $100 \mathrm{~mL}$ infusion (MIMS 2020) in Ireland. Total treatment cost is considerably higher, incorporating other factors such as staffing, health care professional time, expendables (eg cannulas), and the bed cost to administer the infusion. In the UK prices quoted range from $£ 200-300$ by IVF clinics. In comparison, IVIG is significantly more expensive, with costs of $\$ 7000-14,000$ per infusion in the US (Martini et al. 2018), or $£ 1700-£ 2000$ per $25 \mathrm{~g}$ in UK fertility clinics. The other major benefit of IL over alternatives is reduced patient risk and less adverse side effects (Martini et al. 2018), making it a safer and more acceptable choice. Pregnancy outcomes following IL use show a very low rate of adverse events, indicating that it is a safe agent to administer in a RIF/RPL population (Ehrlich et al. 2019). Other studies also report no adverse maternal outcomes (Meng et al. 2016), further supporting the safety profile.

There are still questions, but emerging data shows that IL treatment can improve outcomes in certain groups. Uncertainty persists in that we do not know the optimal diagnostic tests or threshold levels to clearly identify candidates. Like many unlicensed interventions in 

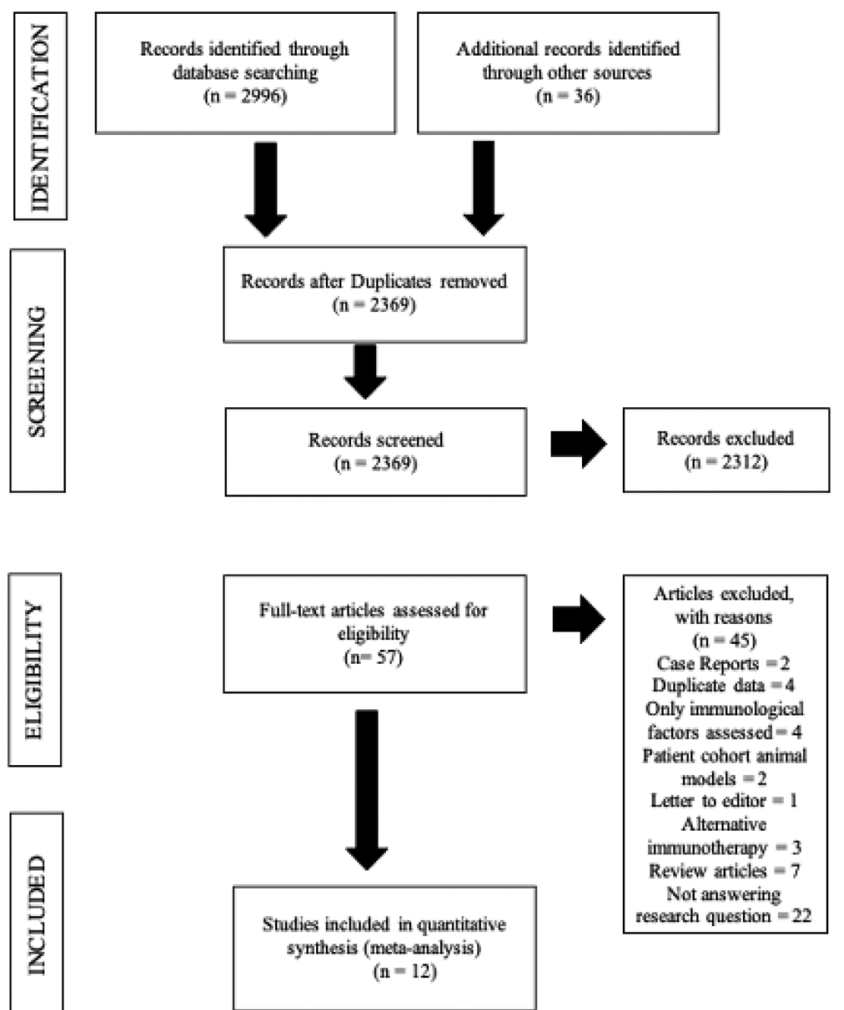

Figure 6 Preferred Reporting Items of Systematic Reviews and MetaAnalysis (PRISMA) flow chart.

reproductive medicine, the large placebo-controlled trials that are needed for conclusive proof are unfortunately unlikely to arise. This is due to many ART centers existing as private stand-alone institutions without the capacity or willingness to develop such trials in their limited patient populations. There are also prohibitive costs associated with industryleadtrialsand thesubsequentapproval/registration process. As a consequence, smaller underpowered or nonrandomized studies do less to advance the knowledge base. High levels of study heterogeneity remain an issue, with the majority of $\mathrm{I}^{2}$ statistics in the $50-90 \%$ range, which may represent substantial heterogeneity. A definitive multicenter study, encompassing a large sample population, with selection criteria based on adverse outcome despite normal cytogenetics, combined with abnormal immune assessment, is the only way to achieve a consensus answer. More also needs to be done to establish the optimal dosage regime and timing of the infusion in relation to implantation, with the number and frequency of repeat infusions still not clearly understood. Perhaps this can be aided by further mechanistic studies to assess which IL regimes can best normalize a diagnosed endometrial immune dysfunction prior to embryo transfer, followed by outcome studies to analyze the effects.

\section{Conclusion}

The meta-analysis identifies that a significant body of evidence exists showing that intralipid infusion can help implantation in those with otherwise unexplained infertility and may improve the LBR in those with recurrent miscarriage in the presence of known immunological risk factors. Although these findings are not enough to establish intralipid use as a routine intervention for RIF/ RPL yet, there is a role for strong consideration in selected cases, especially when standard treatment has failed, and identifiable risk factors are present.

\section{Declaration of interest}

The authors declare that there is no conflict of interest that could be perceived as prejudicing the impartiality of the research reported.

\section{Funding}

This research received no specific grant from any funding agency in the public, commercial or not-for-profit sectors.

\section{Author contribution statement}

Selection and screening process by authors $\mathrm{P} \mathrm{K}$ and $\mathrm{C} \mathrm{H}$. K M contributed to manuscript editing. Process of the literature selection is summarized in PRISMA (Preferred Reporting Items for Systematic Reviews and MetaAnalysis) flow chart (Fig. 6). Any disagreements were resolved by consensus and/or discussion with the senior author $(\mathrm{C} \mathrm{H})$.

\section{References}

Abdolmohammadi-Vahid S, Danaii S, Hamdi K, Jadidi-Niaragh F, Ahmadi M \& Yousefi M 2016 Novel immunotherapeutic approaches for treatment of infertility. Biomedicine and Pharmacotherapy 84 1449-1459. (https://doi.org/10.1016/j. biopha.2016.10.062)

Al-Zebeidi J, Agdi M, Lary S, Al-Obaid S, Salim G \& Al-Jaroudi D 2020 Effect of empiric intravenous intralipid therapy on pregnancy outcome in women with unexplained recurrent implantation failure undergoing intracytoplasmic sperm injection-embryo transfer cycle: a randomized controlled trial. Gynecological Endocrinology 36 131-134. (https://doi.org/10.1080/09513590.2019.1631280)

Bansal AS, Bajardeen B \& Thum MY 2012 The basis and value of currently used immunomodulatory therapies in recurrent miscarriage. Journal of Reproductive Immunology 93 41-51. (https://doi.org/10.1016/j. jri.2011.10.002)

Chaouat G 2007 The Th1/Th2 paradigm: still important in pregnancy? Seminars in Immunopathology 29 95-113. (https://doi.org/10.1007/ s00281-007-0069-0)

Chaouat G, Menu E, Clark DA, Dy M, Minkowski M \& Wegmann TG 1990 Control of fetal survival in CBA x DBA/2 mice by lymphokine therapy. Journal of Reproduction and Fertility 89 447-458. (https://doi.org/10.1530/jrf.0.0890447)

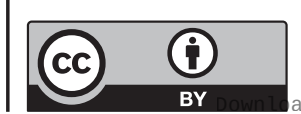

This work is licensed under a Creative Commons Attribution 4.0 International License. 
Check JH \& Check DL 2016 Intravenous intralipid therapy is not beneficial in having a live delivery in women aged 40-42 years with a previous history of miscarriage or failure to conceive despite embryo transfer undergoing in vitro fertilization-embryo transfer. Clinical and Experimental Obstetrics and Gynecology 43 14-15.

Christiansen OB, Nielsen HS \& Kolte AM 2006 Future directions of failed implantation and recurrent miscarriage research. Reproductive Biomedicine Online 13 71-83. (https://doi.org/10.1016/s14726483(10)62018-4)

Clark DA 1994 Intralipid as treatment for recurrent unexplained abortion? American Journal of Reproductive Immunology 32 290-293. (https://doi.org/10.1111/j.1600-0897.1994.tb01128.x)

Clark DA 2010 The power of observation. American Journal of Reproductive Immunology 66 71-75.

Clark DA, Coulam CB \& Stricker RB 2006 Is intravenous immunoglobulins (IVIG) efficacious in early pregnancy failure? A critical review and meta-analysis for patients who fail in vitro fertilization and embryo transfer (IVF). Journal of Assisted Reproduction and Genetics 23 1-13. (https://doi.org/10.1007/s10815-005-9013-1)

Coulam CB 2020 Intralipid treatment for women with reproductive failures. American Journal of Reproductive Immunology $\mathbf{8 5}$ e13290. (https://doi.org/10.1111/aji.13290)

Coulam CB \& Acacio B 2012 Does immunotherapy for treatment of reproductive failure enhance live births? American Journal of Reproductive Immunology 67 296-304. (https://doi.org/10.1111/j.16000897.2012.01111.x)

Coulam C, Bilal M, Beaman K \& Dambaeva S 2020 Decidualization score identifies causes of recurrent implantation failure. Fertility and Sterility 113 14. (https://doi.org/10.1016/j.fertnstert.2020.02.036)

Dakhly DM, Bayoumi YA, Sharkawy M, Gad Allah SH, Hassan MA, Gouda HM, Hashem AT, Hatem DL, Ahmed MF \& El-Khayat W 2016 Intralipid supplementation in women with recurrent spontaneous abortion and elevated levels of natural killer cells. International Journal of Gynaecology and Obstetrics 135 324-327. (https://doi.org/10.1016/j.ijgo.2016.06.026)

Driver I, Feather JW, King PR \& Dawson JB 1989 The optical properties of aqueous suspensions of intralipid a fat emulsion. Physics in Medicine and Biology 34 1927-1930. (https://doi.org/10.1088/00319155/34/12/015)

Ehrlich R, Hall ML, Walkley J \& Sacks G 2019 Intralipid immunotherapy for repeated IVF failure. Fertility and Reproduction $\mathbf{1}$ 154-160. (https://doi.org/10.1142/S2661318219500178)

El-Khayat W \& Sadek ME 2015 Intralipid for repeated implantation failure (RIF): a randomised control trial. Fertility and Sterility 104 E26.

Emmer PM, Veerhoek M, Nelen WLDM, Steegers EAP \& Joosten I 1999 Natural Killer cell reactivity and HLA-G in recurrent spontaneous abortion. Transplantation Proceedings 31 1838-1840. (https://doi. org/10.1016/s0041-1345(99)00182-7)

Ford HB \& Schust DJ 2009 Recurrent pregnancy loss: etiology, diagnosis, and therapy. Reviews in Obstetrics and Gynecology 2 76-83.

Franasiak JM \& Scott RT 2017 Contribution of immunology to implantation failure of euploid embryos. Fertility and Sterility $\mathbf{1 0 7}$ 1279-1283. (https://doi.org/10.1016/j.fertnstert.2017.04.019)

Franasiak JM, Forman EJ, Hong KH, Werner MD, Upham KM, Treff NR \& Scott RT 2014 The nature of aneuploidy with increasing age of the female partner: a review of 15,169 consecutive trophectoderm biopsies evaluated with comprehensive chromosomal screening. Fertility and Sterility 101 656.e1-663.e1. (https://doi. org/10.1016/j.fertnstert.2013.11.004)

Freeman J, Goldmann DA, Smith NE, Sidebottom DG, Epstein MF \& Platt R 1990 Association of intravenous lipid emulsion and coagulase-negative staphylococcal bacteremia in neonatal intensive care units. New England Journal of Medicine 323 301-308. (https://doi. org/10.1056/NEJM199008023230504)

Granato D, Blum S, Rossle C, Le Boucher J, Malnoe A \& Dutot G 2000 Effects of parenteral lipid emulsions with different fatty acid composition on immune cell functions in vitro. Journal of Parenteral and Enteral Nutrition 24 113-118. (https://doi.org/10.1177/0148607100 024002113)

Harrity C, Shkrobot L, Walsh D \& Marron K 2018 ART implantation failure and miscarriage in patients with elevated intracellular cytokine ratios: response to immune support therapy. Fertility Research and Practice 4 7. (https://doi.org/10.1186/s40738-018-0052-6)

Harrity C, Bereir MM, Walsh DJ \& Marron KD 2019 Moving from peripheral blood to local uterine immunophenotype analysis in patients with poor reproductive history: pilot study of a novel technique. Irish Journal of Medical Science 188 893-901. (https://doi. org/10.1007/s11845-018-1933-8)

Horowitz A, Strauss-Albee DM, Leipold M, Kubo J, NematGorgani N, Dogan OC, Dekkar CL, Mackey S, Maecker H, Swan GE, et al. 2013 Genetic and environmental determinants of human NK cell diversity revealed by mass cytometry. Science Translational Medicine 5 208ra145. (https://doi.org/10.1126/ scitranslmed.3006702)

Human Fertilisation and Embryology Authority UK Statistics for IVF and DI Treatment, Storage, and Donation 2020. https://www.hfea.gov.uk/ media/3158/fertility-treatment-2018-trends-and-figures.pdf

Hutton B, Sharma R, Fergusson D, Tinmouth A, Herbert P, Jamieson J \& Walker M 2007 Use of intravenous immunoglobulin for treatment of recurrent miscarriage: a systematic review. BJOG $\mathbf{1 1 4}$ 134-142. (https://doi.org/10.1111/j.1471-0528.2006.01201.x)

Jarvis WR, Highsmith AK, Allen JR \& Haley RW 1983 Polymicrobia bacteremia associated with lipid emulsion in a neonatal intensive care unit. Pediatric Infectious Disease 2 203-208. (https://doi. org/10.1097/00006454-198305000-00006)

Johnson PM, Ramsden GH, Chia KV, Hart CA, Farquharson RG \& Francis WJA 1991 A combined randomised double-blind and open study of trophoblast membrane infusion (TMI) in unexplained recurrent miscarrage. Cellular Molecular Biology of the Materno-Fetal Relationship 212 277-284.

Jung T, Schauer U, Heusser C, Neumann C \& Rieger C 1993 Detection of intracellular cytokines by flow cytometry. Journal of Immunological Methods 159 197-207. (https://doi.org/10.1016/0022-1759(93)90158-4)

Khan L, Qureshi VF, Jabeen T \& Qureshi SAB 2019 Use of intralipid in the management of recurrent implantation failure: an overview. Journal of Natural Science, Biology and Medicine 9 111-114.

King K, Smith S, Chapman M \& Sacks G 2010 Detailed analysis of peripheral blood natural killer (NK) cells in women with recurrent miscarriage. Human Reproduction 25 52-58. (https://doi.org/10.1093/ humrep/dep349)

Koopman LA, Kopcow HD, Rybalov B, Boyson JE, Orange JS, Schatz F, Masch R, Lockwood CJ, Schachter AD, Park PJ, et al. 2003 Human decidual natural killer cells are unique NK cell subset with immunomodulatory potential. Journal of Experimental Medicine 198 1201-1212. (https://doi.org/10.1084/jem.20030305)

Kwak JY, Kwak FM, Ainbinder SW, Ruiz AM \& Beer AE 1996 Elevated peripheral blood natural killer cells are effectively downregulated by immunoglobulin $\mathrm{G}$ infusion in women with recurrent spontaneous abortions. American Journal of Reproductive Immunology 35 363-369. (https://doi.org/10.1111/j.1600-0897.1996. tb00495.x)

Kwak-Kim JY, Chung-Bang HS, Ng SC, Ntrivalas EI, Mangubat CP, Beaman KD, Beer AE \& Gilman-Sachs A 2003 Increased T helper 1 cytokine responses by circulating T cells are present in women with recurrent pregnancy losses and in infertile women with multiple implantation failures after IVF. Human Reproduction 18 767-773. (https://doi.org/10.1093/humrep/deg156)

Lachapelle MH, Miron P, Hemmings R \& Roy DC 1996 Endometrial T, $\mathrm{B}$, and NK cells in patients with recurrent spontaneous abortion. Altered profile and pregnancy outcome. Journal of Immunology 156 4027-4034.

Ledee N, Petitbarat M, Chevrier L, Vitoux D, Vezmar K, Rahmati M, Dubanchet S, Gahery H, Bensussan A \&

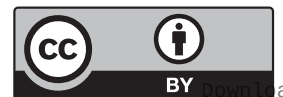

This work is licensed under a Creative Commons Attribution 4.0 International License. 
Chaouat G 2016 The uterine immune profile may help women with repeated unexplained embryo implantation failure after in vitro fertilization. American Journal of Reproductive Immunology 75 388-401. (https://doi.org/10.1111/aji.12483)

Ledee N, Prat-Ellenberg L, Petitbarat M, Chevrier L, Simon C, Irani EE, Vitoux D, Bensussan A \& Chaouat G 2018 a Impact of prednisone in patients with repeated embryo implantation failures: beneficial or deleterious? Journal of Reproductive Immunology 127 11-15. (https://doi.org/10.1016/j.jri.2018.03.003)

Ledee N, Vasseur C, Petitbarat M, Chevrier L, Vezmar K, Dray G, Cheniere S, Lobersztajn A, Vitoux D, Cassuto GN, et al. $2018 b$ Intralipid(R) may represent a new hope for patients with reproductive failures and simultaneously an over-immune endometrial activation. Journal of Reproductive Immunology 130 18-22. (https://doi. org/10.1016/j.jri.2018.09.050)

Li J, Chen Y, Liu C, Hu Y \& Li L 2013 Intravenous immunoglobulin treatment for repeated IVF/ICSI failure and unexplained infertility: a systematic review and a meta-analysis. American Journal of Reproductive Immunology 70 434-447. (https://doi.org/10.1111/aji.12170)

Macklon NS, Ahuja KK \& Fauser B 2019 Building an evidence base for IVF 'add-ons'. Reproductive Biomedicine Online 38 853-856. (https://doi. org/10.1016/j.rbmo.2019.04.005)

Maecker HT, Mccoy JP \& Nussenblatt R 2012 Standardizing immunophenotyping for the Human Immunology Project. Nature Reviews: Immunology 12 191-200. (https://doi.org/10.1038/nri3158)

Marron K, Walsh D \& Harrity C 2019 Detailed endometrial immune assessment of both normal and adverse reproductive outcome populations. Journal of Assisted Reproduction and Genetics 36 199-210. (https://doi.org/10.1007/s10815-018-1300-8)

Martini AE, Jasulaitis S, Fogg LF, Uhler ML \& Hirshfeld-Cytron JE 2018 Evaluating the utility of intralipid infusion to improve live birth rates in patients with recurrent pregnancy loss or recurrent implantation failure. Journal of Human Reproductive Sciences $\mathbf{1 1}$ 261-268. (https://doi.org/10.4103/jhrs.JHRS_28_18)

Meng L, Lin J, Chen L, Wang Z, Liu M, Liu Y, Chen X, Zhu L, Chen H \& Zhang J 2016 Effectiveness and potential mechanisms of intralipid in treating unexplained recurrent spontaneous abortion. Archives of Gynecology and Obstetrics 294 29-39. (https://doi. org/10.1007/s00404-015-3922-8)

Michou VI, Kanavaros P, Athanassiou V, Chronis GB, Stabamas S \& Tsilivakos V 2003 Fraction of the peripheral blood concentration of CD56+/CD16-/CD3- cells in total natural killer cells as an indication of fertility and infertility. Fertility and Sterility $\mathbf{8 0}$ (Supplement 2) 691-697. (https://doi.org/10.1016/s0015-0282(03)00778-7)

MIMS 2020 Intralipid 20\% [Online]. Mims Ireland. Accessed December 2020.

Moffett A \& Shreeve N 2016 Reply: First do no harm: continuing the uterine NK cell debate. Human Reproduction 31 218-219. (https://doi. org/10.1093/humrep/dev290)

Moffett-King A 2002 Natural killer cells and pregnancy. Nature Reviews: Immunology 2 656-663. (https://doi.org/10.1038/nri886)

Muscaritoli M, Conversano L, Torelli GF, Arcese W, Capria S, Cangiano C, Falcone C \& Rossi Fanelli F 1998 Clinical and metabolic effects of different parenteral nutrition regimens in patients undergoing allogeneic bone marrow transplantation. Transplantation 66 610-616. (https://doi.org/10.1097/00007890-199809150-00011)

Ndukwe G 2011 Recurrent embryo implantation failure after in vitro fertilisation: improved outcome following intralipid infusion in women with elevated T Helper 1 response. Human Fertility 14 20-21.

Ota DM, Jessup JM, Babcock GF, Kirschbaum L, Mountain CF, Mcmurtrey MJ \& Copeland 3rd EM 1985 Immune function during intravenous administration of a soybean oil emulsion. Journal of Parenteral and Enteral Nutrition 9 23-27. (https://doi. org/10.1177/014860718500900123)

Pirtea P, Cicinelli E, De Nola R, De Ziegler D \& Ayoubi JM 2021 Endometrial causes of recurrent pregnancy losses: endometriosis, adenomyosis, and chronic endometritis. Fertility and Sterility $\mathbf{1 1 5}$ 546-560. (https://doi.org/10.1016/j.fertnstert.2020.12.010)

Placais L, Kolanska K, Kraiem YB, Cohen J, Suner L, Bornes M, Sedille L, Rosefort A, D'Argent EM, Selleret L, et al. 2020 Intralipid therapy for unexplained recurrent miscarriage and implantation failure: case-series and literature review. European Journal of Obstetrics, Gynecology, and Reproductive Biology 252 100-104. (https:// doi.org/10.1016/j.ejogrb.2020.06.017)

Quenby S, Kalumbi C, Bates M, Farquharson R \& Vince G 2005 Prednisolone reduces preconceptual endometrial natural killer cells in women with recurrent miscarriage. Fertility and Sterility 84 980-984. (https://doi.org/10.1016/j.fertnstert.2005.05.012)

Raziel A, Herman A, Bukovsky I, Caspi E \& Ron-El R 1996 Intravenous immunoglobulin treatment of pregnant patients with unexplained recurrent abortions. Human Reproduction 11 711-715. (https://doi.org/10.1093/oxfordjournals.humrep.a019238)

Rimmer MP, Fishwick K, Henderson I, Chinn D, Al Wattar BH \& Quenby S 2021 Quantifying CD138+ cells in the endometrium to assess chronic endometritis in women at risk of recurrent pregnancy loss: a prospective cohort study and rapid review. Journal of Obstetrics and Gynaecology Research 47 689-697. (https://doi.org/10.1111/jog.14585)

Robertson MJ \& Ritz J 1990 Biology and clinical relevance of human natural killer cells. Blood 76 2421-2438.

Roussev RG, Ng SC \& Coulam CB 2007 Natural killer cell functional activity suppression by intravenous immunoglobulin, intralipid and soluble human leukocyte antigen-G. American Journal of Reproductive Immunology 57 262-269. (https://doi.org/10.1111/j.16000897.2007.00473.x)

Roussev RG, Acacio B, Ng SC \& Coulam CB 2008 Duration of intralipid's suppressive effect on NK cell's functional activity. American Journal of Reproductive Immunology 60 258-263. (https://doi. org/10.1111/j.1600-0897.2008.00621.x)

Ruan YC, Guo JH, Liu X, Zhang R, Tsang LL, Dong JD, Chen H, Yu MK, Jiang X, Zhang XH, et al. 2012 Activation of the epithelial $\mathrm{Na}+$ channel triggers prostaglandin $\mathrm{E}(2)$ release and production required for embryo implantation. Nature Medicine 18 1112-1117. (https://doi.org/10.1038/nm.2771)

Ruiz JE, Kwak JY, Baum L, Gilman-Sachs A, Beaman KD, Kim YB \& Beer AE 1996 Effect of intravenous immunoglobulin G on natural killer cell cytotoxicity in vitro in women with recurrent spontaneous abortion. Journal of Reproductive Immunology 31 125-141. (https://doi. org/10.1016/0165-0378(96)00969-2)

Sacks G, Yang Y, Gowen E, Smith S, Fay L \& Chapman M 2012 Detailed analysis of peripheral blood natural killer cells in women with repeated IVF failure. American Journal of Reproductive Immunology 67 434-442. (https://doi.org/10.1111/j.1600-0897.2012.01105.x)

Salker MS, Christian M, Steel JH, Nautiyal J, Lavery S, Trew G, Webster Z, Al-Sabbagh M, Puchchakayala G, Foller M, et al. 2011 Deregulation of the serum- and glucocorticoid-inducible kinase SGK1 in the endometrium causes reproductive failure. Nature Medicine 17 1509-1513. (https://doi.org/10.1038/nm.2498)

Savasi VM, Mandia L, Laoreti A \& Cetin I 2016 Maternal and fetal outcomes in oocyte donation pregnancies. Human Reproduction Update 22 620-633. (https://doi.org/10.1093/humupd/dmw012)

Sedman PC, Somers SS, Ramsden CW, Brennan TG \& Guillou PJ 1991 Effects of different lipid emulsions on lymphocyte function during total parenteral nutrition. British Journal of Surgery $\mathbf{7 8}$ 1396-1399. (https://doi.org/10.1002/bjs.1800781142)

Seshadri S \& Sunkara SK 2014 Natural killer cells in female infertility and recurrent miscarriage: a systematic review and meta-analysis. Human Reproduction Update 20 429-438. (https://doi.org/10.1093/ humupd/dmt056)

Sewell WA \& Jolles S 2002 Immunomodulatory action of intravenous immunoglobulin. Immunology 107 387-393. (https://doi.org/10.1046/ j.1365-2567.2002.01545.x) Published by Bioscientifica Ltd

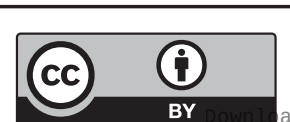

This work is licensed under a Creative Commons Attribution 4.0 International License. 
Shreeve N \& Sadek K 2012 Intralipid therapy for recurrent implantation failure: new hope or false dawn? Journal of Reproductive Immunology 93 38-40. (https://doi.org/10.1016/j.jri.2011.11.003)

Singh N, Davis AA, Kumar S \& Kriplani A 2019 The effect of administration of intravenous intralipid on pregnancy outcomes in women with implantation failure after IVF/ICSI with nondonor oocytes: a randomised controlled trial. European Journal of Obstetrics, Gynecology, and Reproductive Biology 240 45-51. (https://doi. org/10.1016/j.ejogrb.2019.06.007)

Snydman DR, Murray SA, Kornfeld SJ, Majka JA \& Ellis CA 1982 Total parenteral nutrition-related infections. Prospective epidemiologic study using semiquantitative methods. American Journal of Medicine 73 695-699. (https://doi.org/10.1016/00029343(82)90412-0)

Souza SS, Ferriani RA, Santos CMP \& Voltarelli JC 2002 Immunological evaluation of patients with recurrent abortion. Journal of Reproductive Immunology 56 111-121. (https://doi.org/10.1016/s01650378(01)00145-0)

Szereday L, Varga P \& Szekeres-Bartho J 1997 Cytokine production by lymphocytes in pregnancy. American Journal of Reproductive Immunology 38 418-422. (https://doi.org/10.1111/j.1600-0897.1997. tb00321.x)

Tang AW, Alfirevic Z, Turner MA, Drury JA, Small R \& Quenby S 2013 A feasibility trial of screening women with idiopathic recurrent miscarriage for high uterine natural killer cell density and randomizing to prednisolone or placebo when pregnant. Human Reproduction 28 1743-1752. (https://doi.org/10.1093/humrep/det117)

Tezuka H, Sawada H, Sakoda H, Itoh K, Nishikori M, Amagai T, Uchino H \& Mori KJ 1988 Suppression of genetic resistance to bone marrow grafts and natural killer activity by administration of fat emulsion. Experimental Hematology 16 609-612.

Thum MY, Bhaskaran S, Abdalla HI, Ford B, Sumar N, Shehata H \& Bansal AS 2004 An increase in the absolute count of CD56dimCD16+CD69+ NK cells in the peripheral blood is associated with a poorer IVF treatment and pregnancy outcome. Human Reproduction 19 2395-2400. (https://doi.org/10.1093/humrep/deh378)

van Mourik MS, Macklon NS \& Heijnen CJ 2009 Embryonic implantation: cytokines, adhesion molecules, and immune cells in establishing an implantation environment. Journal of Leukocyte Biology 85 4-19. (https://doi.org/10.1189/jlb.0708395)

Vasquez YM, Wang X, Wetendorf M, Franco HL, Mo Q, Wang T, Lanz RB, Young SL, Lessey BA, Spencer TE, et al. 2018 FOXO1 regulates uterine epithelial integrity and progesterone receptor expression critical for embryo implantation. PLoS Genetics 14 e1007787. (https://doi.org/10.1371/journal.pgen.1007787)

Wang Q, Li TC, Wu YP, Cocksedge KA, Fu YS, Kong QY \& Yao SZ 2008 Reappraisal of peripheral NK cells in women with recurrent miscarriage. Reproductive Biomedicine Online 17 814-819. (https://doi. org/10.1016/s1472-6483(10)60410-5)

Wegmann TG 1989-1990 The cytokine basis for cross-talk between the maternal immune and reproductive systems. Current Opinion in Immunology 2 765-769. (https://doi.org/10.1016/09527915(90)90048-1)

Wegmann TG, Waters CA, Drell DW \& Carlson GA 1979 Pregnant mice are not primed but can be primed to fetal alloantigens. PNAS 76 2410-2414. (https://doi.org/10.1073/pnas.76.5.2410)

Wolff MV, Ursel S, Hahn U, Steldinger R \& Strowitzki T 2003 Glucose transporter proteins (GLUT) in human endometrium: expression, regulation, and function throughout the menstrual cycle and in early pregnancy. Journal of Clinical Endocrinology and Metabolism 88 3885-3892. (https://doi.org/10.1210/jc.2002-021890)

Wretlind A 1981 Development of fat emulsions. Journal of Parenteral and Enteral Nutrition 5 230-235. (https://doi.org/10.1177/01486071810050 03230)

Yamada H, Morikawa M, Kato EH, Shimada S, Kobashi G \& Minakami H 2003 Pre-conceptional natural killer cell activity and percentage as predictors of biochemical pregnancy and spontaneous abortion with normal chromosome karyotype. American Journal of Reproductive Immunology 50 351-354. (https://doi.org/10.1034/j.16000897.2003.00095.x)

Zenclussen AC, Gerlof K, Zenclussen ML, Sollwedel A, Bertoja AZ, Ritter T, Kotsch K, Leber J \& Volk HD 2005 Abnormal T-cell reactivity against paternal antigens in spontaneous abortion: adoptive transfer of pregnancy-induced CD4+CD25+ T regulatory cells prevents fetal rejection in a murine abortion model. American Journal of Pathology 166 811-822. (https://doi.org/10.1016/S00029440(10)62302-4)

Received in final form 31 May 2021

Accepted 3 June 2021

Accepted Manuscript published online 4 June 2021
(C) 2021 The authors Published by Bioscientifica Ltd

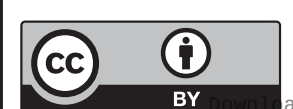

This work is licensed under a Creative Commons Attribution 4.0 International License. 